\title{
Permeation grouting and excavation at Victoria station, London
}

1 Megan Packer BSc(Hons), BA, MSC, DIC, CGeol, FGS Associate, Pells Sullivan Meynink, Sydney, NSW, Australia; formerly of Tony Gee \& Partners, Surrey, UK (corresponding author: Megan.Packer@psm.com.au)

2 Richard Newman BSC, MSc, DIC, CEng, MICE Geotechnical Director, Tony Gee \& Partners, Surrey, UK
3 Craig Prangley MEng, CEng, MICE Project Director, Taylor Woodrow, London, UK

4 Ian Heath CEng, FIMM

SCL Construction Manager, Costain Group PLC, London, UK Tunnel Manager, formerly of BAM Nuttall, London, UK
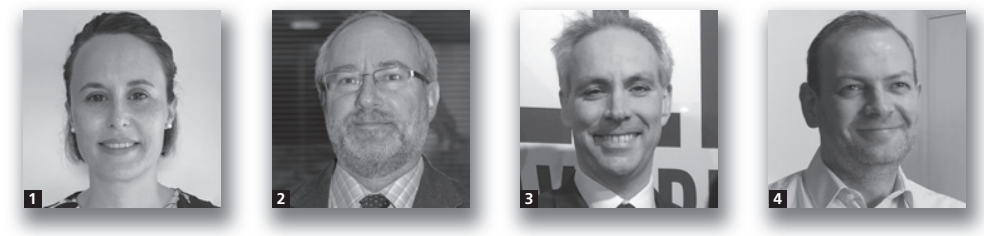

Paid area link 6 (Pal6) underpass, a crucial tunnel connection of London Underground's Victoria station upgrade project, was engineered within notoriously difficult sub-artesian granular River Terrace Deposits (RTD) immediately below the Victorian-age District and Circle line masonry tunnel, a structure highly sensitive to ground displacements. Due to the proximity of the overlying operational railway, the consequences of ground movement were of very high risk. Historic tunnel construction in the heterogeneous RTD had limited success with permeation grouting, and face losses and instabilities occurred. For the case of Pal6, the railway tunnel overhead magnified the difficulties. Permeation grouting still remained the most feasible stabilising option, but only with significant improvements in both grouting technique and grout types. A low-risk tunnelled solution, using a bespoke and sophisticated construction approach, enabled safe continuous excavation within the severely restricted structural constraints. Successful tunnelling demanded: complete sequence recovery of the RTD for accurate soil characterisation for design of the grouting system; caution with permeation grouting; appropriate grout selection to promote permeation without claquage (uncontrolled fracturing by grout with its consequent irregular distribution), thus precisely targeting discrete zones; uniform treatment; and observational control by monitoring real-time ground movements.

\section{Notation}

$C_{\mathrm{H}} \quad$ constant in Hazen's formula

$D_{10} \quad$ particle size below which $10 \%$ of particles lie

$k \quad$ permeability

\section{Introduction}

Paid area link 6 (Pal6) provides the only access between the new north and enlarged south ticket halls of London Underground's complex Victoria station upgrade (VSU) project, a major scheme to relieve severe congestion and overcrowding and provide step-free access at the UK's second busiest terminus. The station upgrade, which was undertaken by a joint venture between Taylor Woodrow and BAM Nuttall, involved $300 \mathrm{~m}$ of interconnecting pedestrian tunnels known as 'paid area links' (Pals). A general arrangement plan of the VSU project is shown in Figure 1. The Pal6 underpass, a crucial connection of the overall scheme, was engineered within challenging water-bearing sands and gravels. It is located immediately below the existing Victorian-age District and Circle (D\&C) line masonry tunnel, for which train operations were very sensitive to rail deflections. The consequences of construction-induced ground displacements or soil-face collapses could affect the safe operation of the railway or demand regular tamping during engineering hours.

A solution that did not require extensive track closures was essential. Challenging the more traditional approach of a piled wall installed from within the existing D\&C tunnel, the combination of a sophisticated structural solution, extensive ground improvement and intricate works sequencing facilitated the successful completion of Pal6. A bespoke and detailed construction approach was used that enabled safe continuous excavation within the limited (and inaccessible from ground level) structural envelope. The major advantage of this scheme was that it needed just a single railway track possession of $6 \mathrm{~d}$ (over Christmas 2014) - a significant reduction from the extensive weekend possessions required by a more conservative approach. Integration of temporary and permanent works enabled safe construction, ensuring the tunnellers' safety, with absolute minimal disruption to passengers.

The construction method and temporary works allowed for a permanent reinforced concrete (RC) box to be constructed directly below the D\&C tunnel. The $750 \mathrm{~mm}$ thick box 


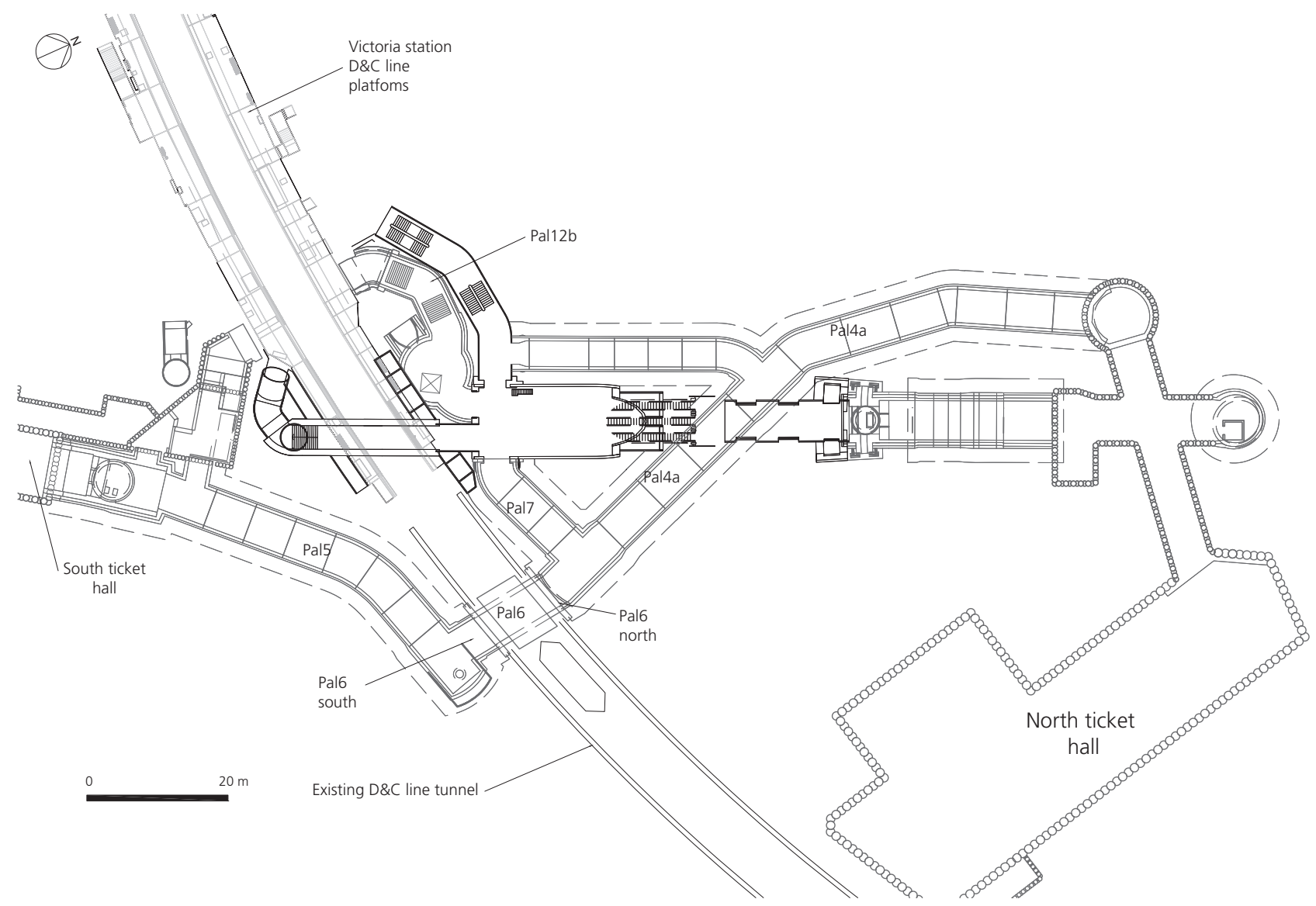

Figure 1. VSU project general arrangement

structure (internal dimensions of $4.7 \mathrm{~m}$ width, $13.5 \mathrm{~m}$ length and $2.8 \mathrm{~m}$ height) was formed using in situ $\mathrm{RC}$ and was designed to be watertight. The box supports the D\&C tunnel foundation and the track. At completion, the distance between the underside of the Pal6 roof slab and the top of rail was just $1.3 \mathrm{~m}$.

Pal6 was constructed in mixed-face ground conditions, the upper section consisting of water-bearing sands and gravels of River Terrace Deposits (RTD) and the lower section the underlying stiff London Clay. The most significant geotechnical challenge of the project was stabilising the RTD to permit safe and stable excavation. These granular soils are of naturally high permeability with a piezometric head several metres higher than the Pal6 roof level.

The adjacent VSU pedestrian tunnels (Pal4a, Pal5 and Pal7; see Figure 1 for the general arrangement) were constructed using sprayed fibre-reinforced concrete (SFRC) techniques within an envelope of jet-grouted RTD, creating dry and stable excavation conditions. Jet grouting for Pal6 was not possible due to inaccessibility for constructing grouting columns directly below the D\&C tunnel.
The scheme relied on reducing the porosity of the RTD to minimise water ingress and unstable flowing conditions. Additionally, its compressive strength needed to be improved for adequate bearing capacity during critical construction stages. Permeation grouting was selected due to the immediate proximity of the D\&C running tunnel. Grouting relating to the nature of the RTD was needed to permeate the voids and, in doing so, checking for any signs of claquage. The accurate and repetitive placement of grout necessitated tubesà-manchettes (Tàms) installed from a temporary headwall at the end of the adjacent tunnel, Pal4a (Figure 2). Conventional drilling to install the horizontal Tàms carried a high risk of ground loss, with unacceptable ground movements, and this was mitigated through use of a closed drilling system.

Excavation through the sub-artesian granular RTD immediately below the operational railway demanded

accurate characterisation of the variable RTD sequence

- appropriate grout selection to promote permeation (avoiding fracture or claquage and precisely targeting discrete zones)

- uniform treatment throughout 


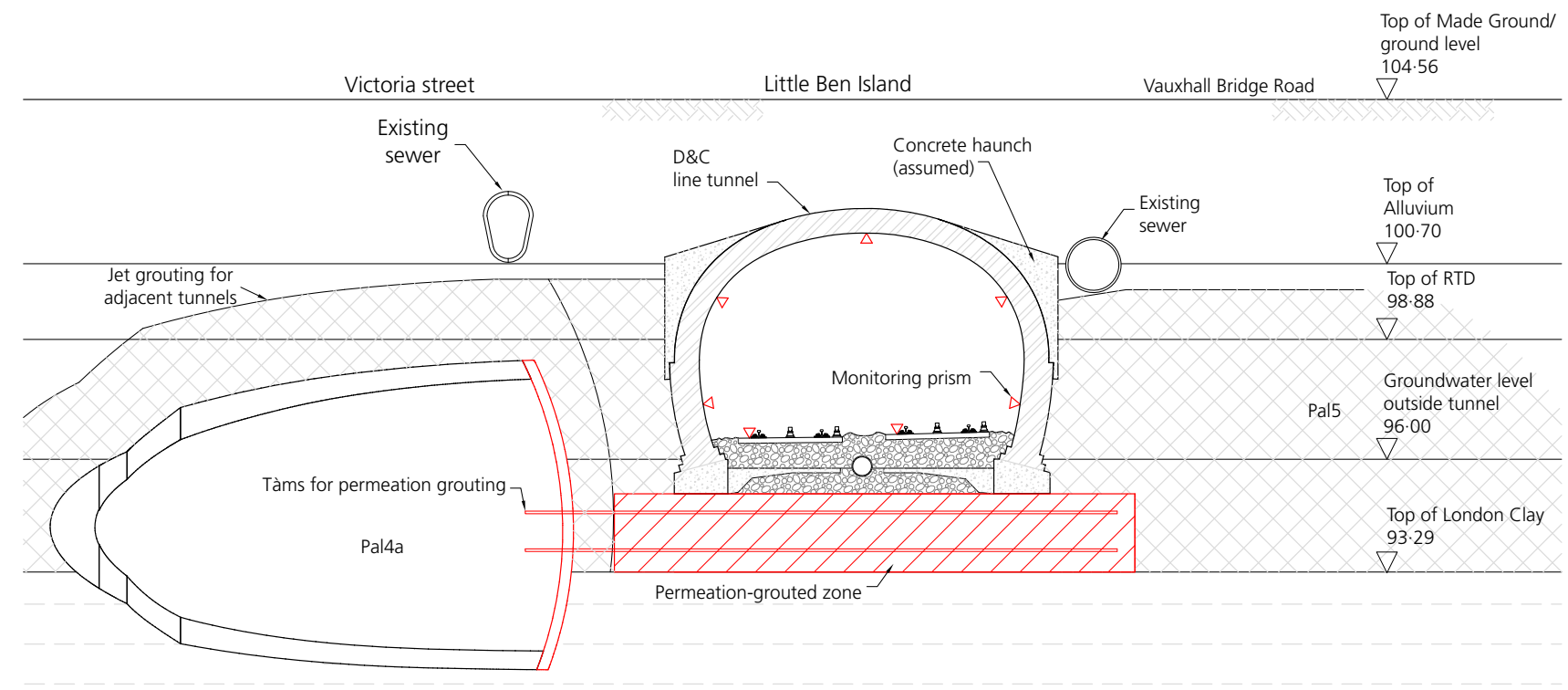

Figure 2. Pal6 permeation-grouted zone

post-treatment verification testing of effectiveness and

- observational control by monitoring real-time ground movements to ensure permeation of the soil rather than displacement.

Accurate and complete characterisation of the RTD (in terms of heterogeneity and particle size distribution) was crucial for grouting design, including actual grout selection. Soil cores obtained using resonance (sonic) drilling permitted accurate logging of the complete RTD sequence as had never been possible before, capturing both fines and local variations. This enabled selection of appropriate ultrafine, microfine and chemical grouts to target discrete RTD horizons.

Successful permeation grouting, along with real-time monitoring systems and a carefully sequenced (and continuously reviewed) excavation enabled safe operation of the D\&C line at all times. Protection of its structural integrity was maintained throughout, along with the adjacent third-party subterranean sewers.

\section{Geological challenges}

The excavation conditions imposed a number of risks to both the temporary and permanent works. The following were of primary concern.

(a) Stability of the excavation face. Untreated RTD, particularly with the influence of the localised hydrogeological regime, would be unstable. Therefore, a robust ground improvement scheme to achieve a barrier to groundwater flow was required to enable safe excavation within these sub-artesian sands and gravels. During construction, validation testing, pilot holes and additional grouting were conducted as a safeguarding measure.

(b) Groundwater control. The hydrostatic head was several metres above the Pal6 roof level and the localised flow regime was dominated by high rates of flow into the D\&C track drainage system.

(c) Vertical and lateral heterogeneity of the RTD and the presence of fine-grained lenses. Previous permeation grouting works at Victoria station (i.e. the congestion relief works in 1992) failed to achieve adequate permeation in areas containing lenses of silt, leaving zones of untreated running materials. If exposed during tunnelling, untreated zones of slightly higher fines content would flow into the excavation, causing instability and the risk of unacceptable ground loss.

(d) 'Groutability'. The suitability of permeation grouting techniques within the RTD was of critical importance. The distribution and heterogeneity of different particle size distribution profiles was key to designing appropriate ground treatment works.

\section{Ground model}

The ground conditions at Victoria station are typical of those of central London, comprising Made Ground at the surface overlying the superficial sequence of Alluvium and RTD. These, in turn, overlie the $\sim 45 \mathrm{~m}$ thick deposit of London Clay. A stratigraphic summary is provided in Table 1. The Pal6 excavation was centred over the interface between the RTD and London Clay. 
Table 1. Stratigraphic summary and interpreted design geotechnical parameters

\begin{tabular}{|c|c|c|}
\hline $\begin{array}{l}\text { Depth to top of } \\
\text { strata: } \mathrm{mbgl}\end{array}$ & Stratum & Description \\
\hline 0 & Made Ground & Slightly sandy fine to coarse gravel comprising flint, brick and concrete fragments \\
\hline $3 \cdot 6-4 \cdot 0$ & Alluvium & Soft bluish dark grey mottled black organic clay \\
\hline $4 \cdot 4-6 \cdot 2$ & RTD & $\begin{array}{l}\text { Orange-brown fine to coarse sand with occasional medium to coarse flint gravel } \\
\text { Slightly gravelly medium to coarse sand over sandy angular to sub-rounded fine to coarse gravel }\end{array}$ \\
\hline $10 \cdot 9-11 \cdot 8$ & $\begin{array}{l}\text { London Clay } \\
\text { (Division B) }\end{array}$ & $\begin{array}{l}\text { Firm to stiff brownish grey very closely fissured clay with occasional pockets of dark grey fine sand and } \\
\text { bioturbation. Some partings of cemented silt }\end{array}$ \\
\hline
\end{tabular}

\subsection{Ground investigations}

Local ground conditions have been well explored through a series of previous ground investigations dating from 1988 to 2012. The three most recent were commissioned for the VSU scheme. Completed in March 2013, a further highly targeted ground investigation was carried out specifically for Pal6. Accurate and reliable characterisation of the RTD and the RTD-London Clay interface were the primary foci as the design approach relied on the ability to grout the RTD successfully. A review of existing geotechnical data indicated that the RTD properties were variable, with heterogeneity especially prevalent in the grain size distributions.

The use of rota-sonic drilling for uncompromised recovery of the sands and gravels enabled the RTD to be analysed as a complete, continuous, undisturbed soil core, thereby providing high confidence in the geotechnical testing results. This was quite possibly the first proven application of rota-sonic drilling for permeation grouting design, allowing discrete sub-units within the RTD to be identified and samples of the various stratigraphic sequences to be taken. Figure 3 shows examples of the recovered intact soil sequence. This information was crucial to the success of permeation grouting as the penetrability of grouts is highly dependent on the fraction of fines. Incorrect determination of particle size distributions could lead to the selection of incompatible injection techniques and grouting materials.

The findings indicated that, despite the RTD at Pal6 exhibiting a high degree of variability, the overall fines content was less than $14 \%$, but typically lower than $6 \%$ (Figure 4 ). The average permeability of the RTD was calculated as $1.4 \times 10^{-4} \mathrm{~m} / \mathrm{s}$ using Hazen's formula ( $k=C_{\mathrm{H}} D_{10}{ }^{2}$ where $D_{10}$ is the particle size (in metres) below which $10 \%$ of the particles lie and $C_{\mathrm{H}}$ is a constant) (Hazen, 1892). A $C_{\mathrm{H}}$ value of 0.0016 was applied, as suggested by Lambe and Whitman (1969) for silty sands to coarse gravels. Hazen's formula was developed for the design of sand filters for water purification (i.e. near uniformly graded washed sands) and is thus not strictly appropriate for natural soils as it tends to overestimates in situ permeability. This is apparent from the results shown in Figure 5, and can lead to misjudgements regarding the soil 'groutability'. In light of this, in situ variable-head testing was conducted in standpipe piezometers during the site investigation phase and the results indicated a typical permeability of approximately $1 \cdot 2 \times 10^{-5} \mathrm{~m} / \mathrm{s}$.
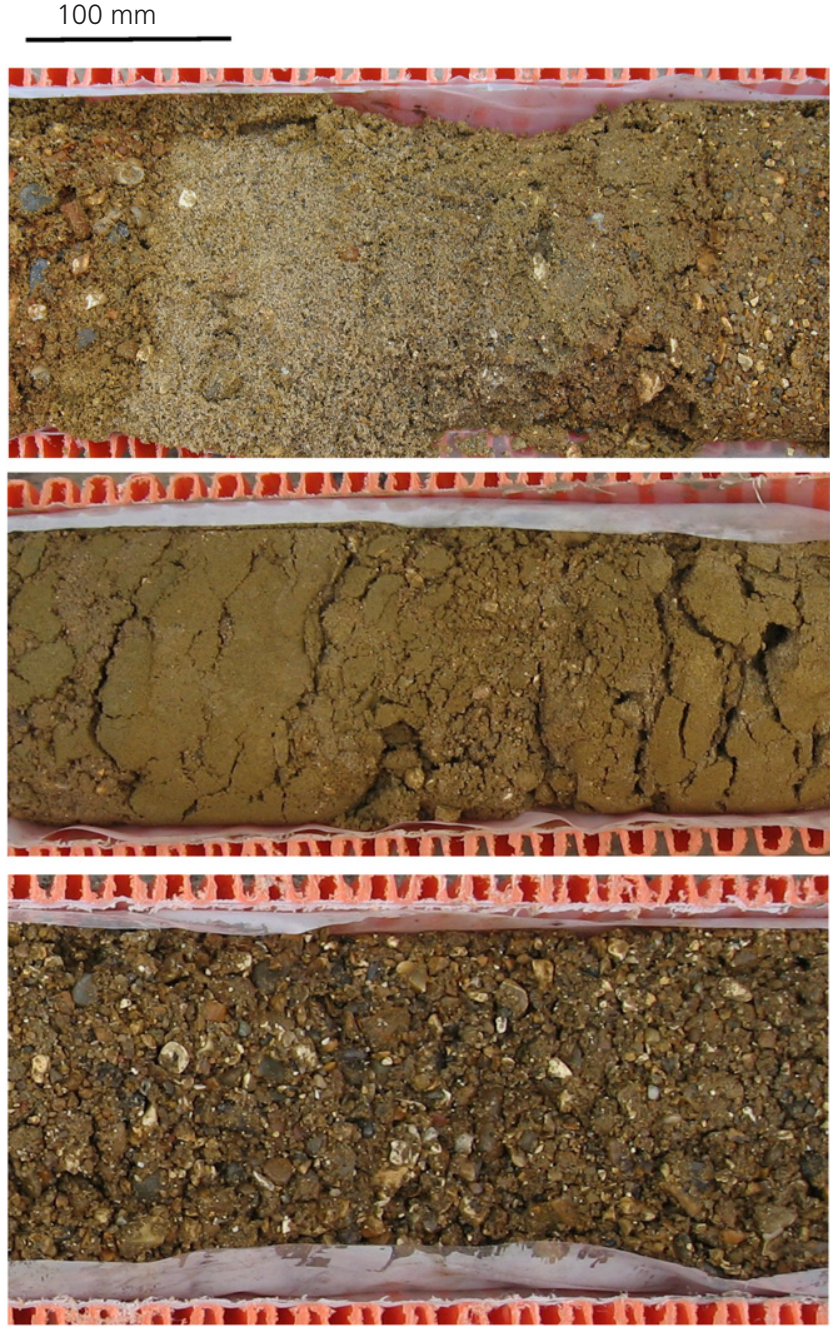

Figure 3. Examples of continuous undisturbed rota-sonic soil cores

Based on the particle size distribution and in situ permeability it was determined that successful permeation grouting using microfine or extrafine cementitious grouts was achievable. Microfine and ultrafine grouts were defined as cementitious binders having a composition where $95 \%$ of all particles had a diameter of $<20 \mu \mathrm{m}$ and $<10 \mu \mathrm{m}$, respectively. Permeability estimates and in situ test results for the Pal6 RTD samples are presented in Figure 5 with respect to grouting limits from Littlejohn (1983). 


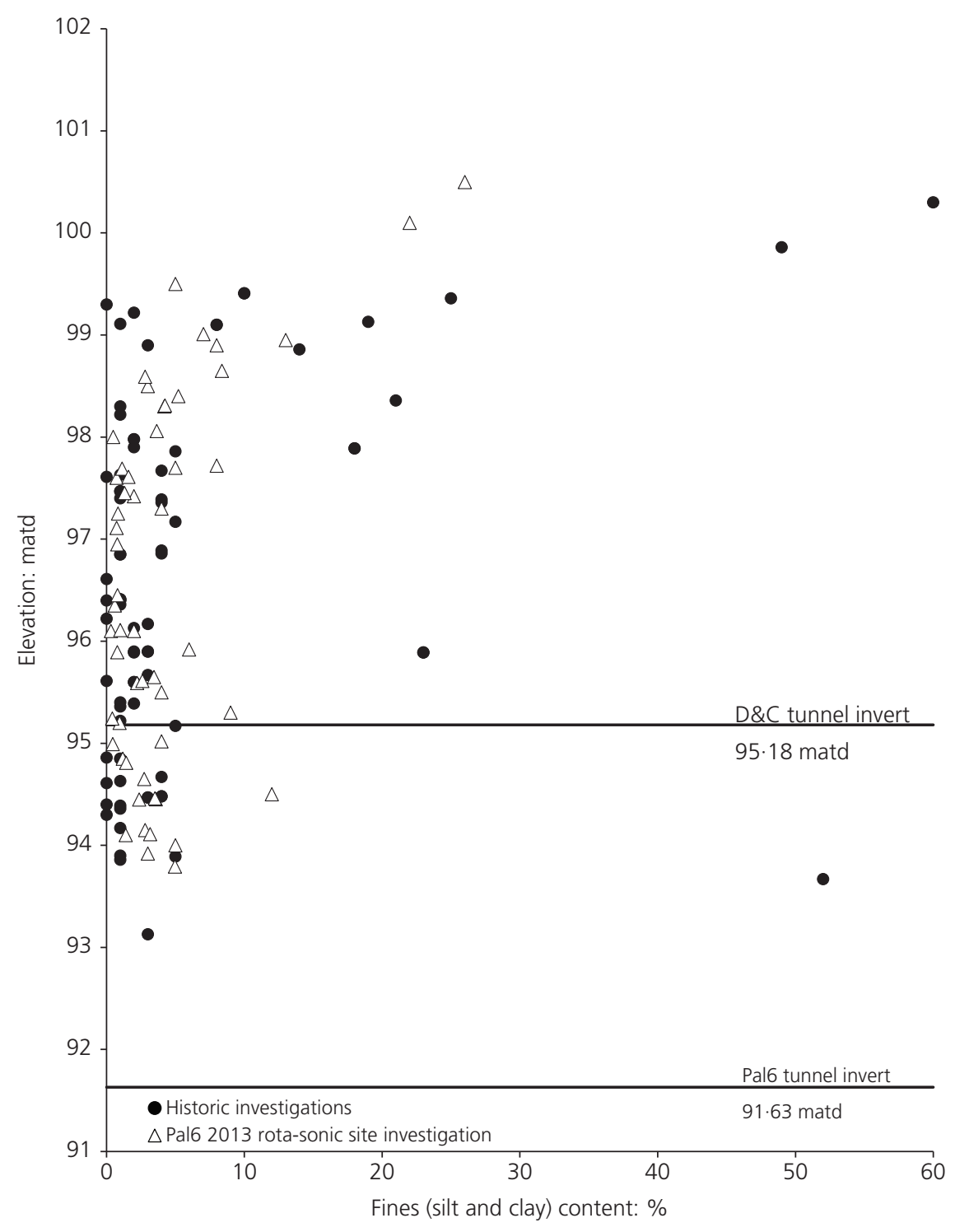

Figure 4. RTD fines content

The groundwater level at Pal6 was reasonably stable at 96 matd (metres above tunnel datum) (tunnel datum was $100 \mathrm{~m}$ lower than Ordnance Datum) (8.5 mbgl (metres below ground level)), $1 \mathrm{~m}$ lower than the surrounding design groundwater levels for the wider VSU project. The under-track drainage channel within the existing D\&C line running tunnel controls the localised groundwater flow regime. High flow rates have been historically observed in this drainage channel, which consequently may have washed fines out from adjacent soils periodically over time.

\section{Structural design constraints}

The sequence of construction was separated into the three main stages of

- installation of the roof slab and needle beams

(Figure 6) installation of temporary works support frame and tunnel excavation (Figures 7-9)

n installation of permanent works (Figure 10).

The RC roof slab also contained embedded steelwork comprising $355.6 \mathrm{~mm}$ outer diameter circular hollow section sleeves encapsulating $323.9 \mathrm{~mm}$ outer diameter needles, steel edge beams and an aqueduct for track drainage. The roof slab was designed to provide structural support to the track bed and tunnel walls in the temporary and permanent conditions, allowing construction of the permanent box below. During subsequent stages, the needles were extracted and grouted into place through cored holes from hand-excavated galleries outside the tunnel. The ends of the extracted needles were then encapsulated within $\mathrm{RC}$ beams to provide a means 


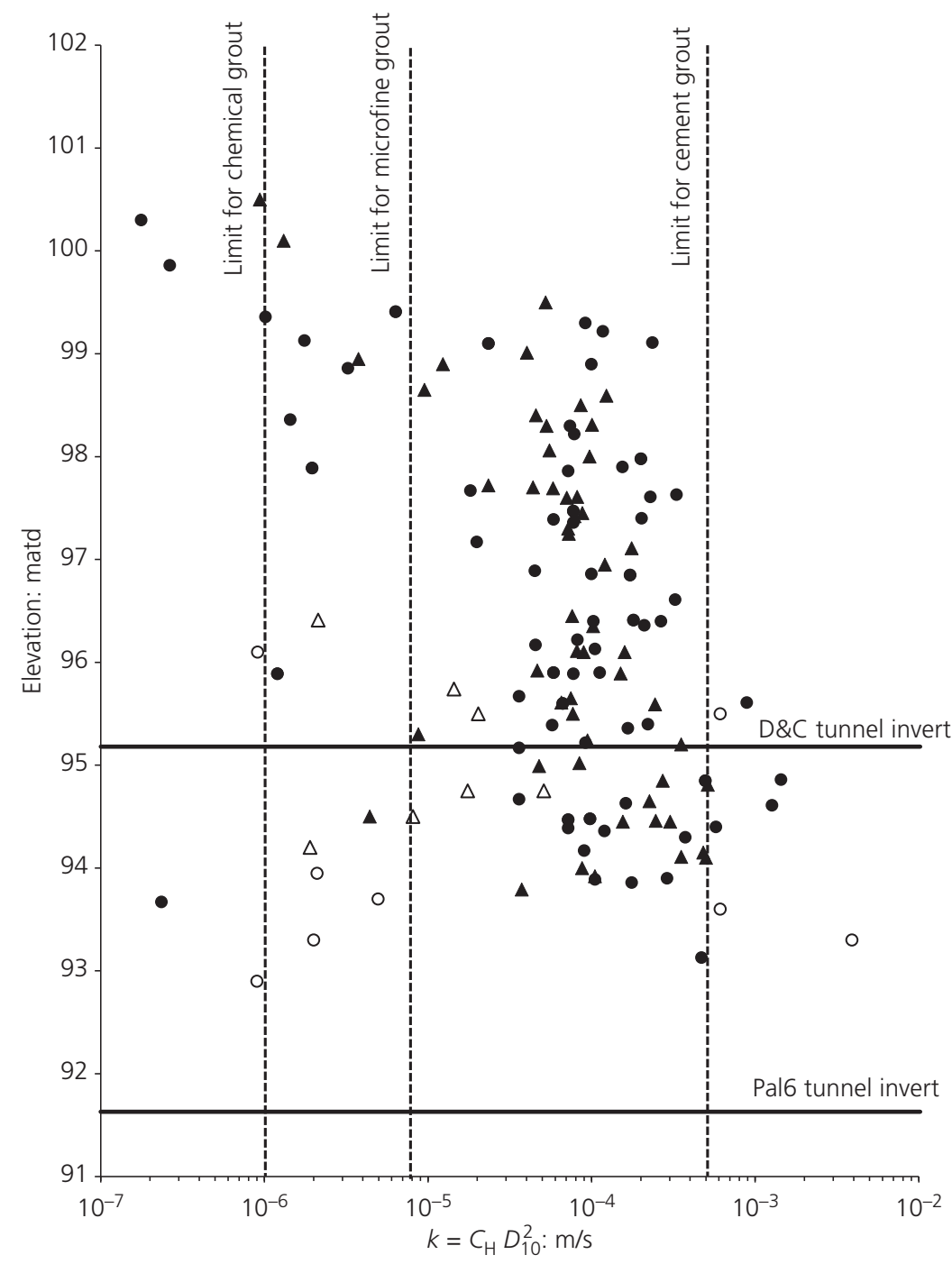

- Historic investigations (Hazen formula)

A Pal6 2013 rota-sonic (Hazen formula) O Historic investigations (in situ tests)

Figure 5. Grout suitability with respect to RTD permeability

of supporting the brick tunnel as the top-down construction progressed.

Extensive temporary works (including a number of timbered headings, the smallest with a cross-section of just $1.5 \mathrm{~m} \times 1.5 \mathrm{~m}$ ) were required to form the access headings for the needle beams, low-level foundations and temporary columns. Temporary deeplevel foundations were used to support the roof construction and associated loads from the D\&C tunnel and track bed in the temporary condition. These were constructed in hand-excavated headings supported by steel frames to maximise the foundation width and access from an adit connecting from the adjacent Pal5.

With the temporary foundations complete, a carefully sequenced series of eight excavations and column installation followed. Columns were installed in three sections with hydraulic jacks at the slab soffit to introduce calculated preload to mitigate deflections and settlements.

Safe mining of the remaining soil under the roof slab required a method of lateral retention of soil and groundwater. Bulk excavation then proceeded sequentially, protected by temporary SFRC side arches to allow the floor and walls of the box structure to be completed, encapsulating the temporary columns. Excavation was conducted in 12 individual $1 \mathrm{~m}$ wide headings from north to south (Figure 8), with hold points for validation probing and further grouting as required. Figure 9 shows a photograph of the bulk excavation with the temporary steel props protectively wrapped. Figure 10 shows the integrated temporary and permanent works configuration of Pal6. 
Geotechnical Engineering

Volume 171 Issue GE3
Permeation grouting and excavation

at Victoria station, London

Packer, Newman, Prangley and Heath

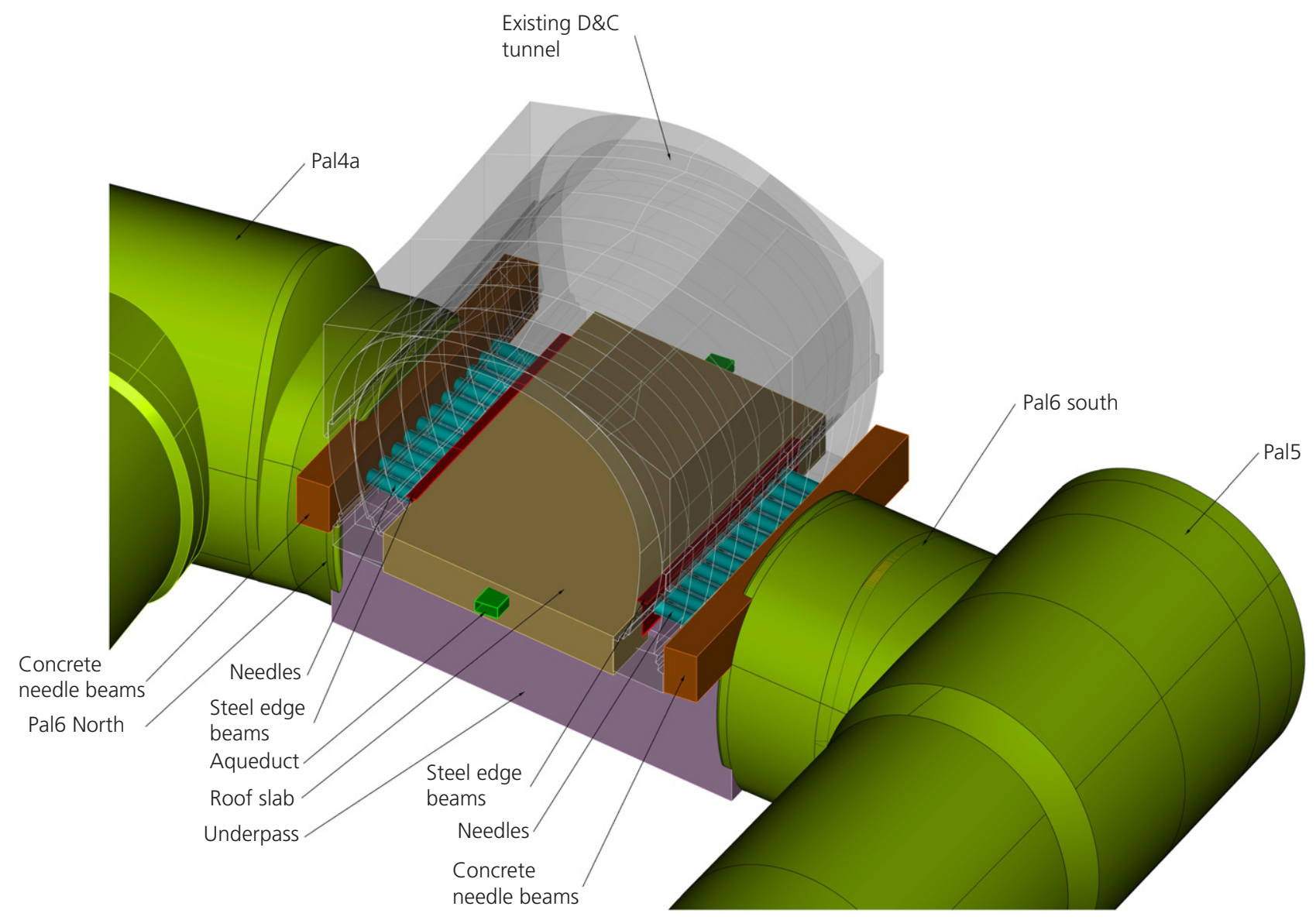

Figure 6. Pal6 roof slab configuration within the existing D\&C tunnel

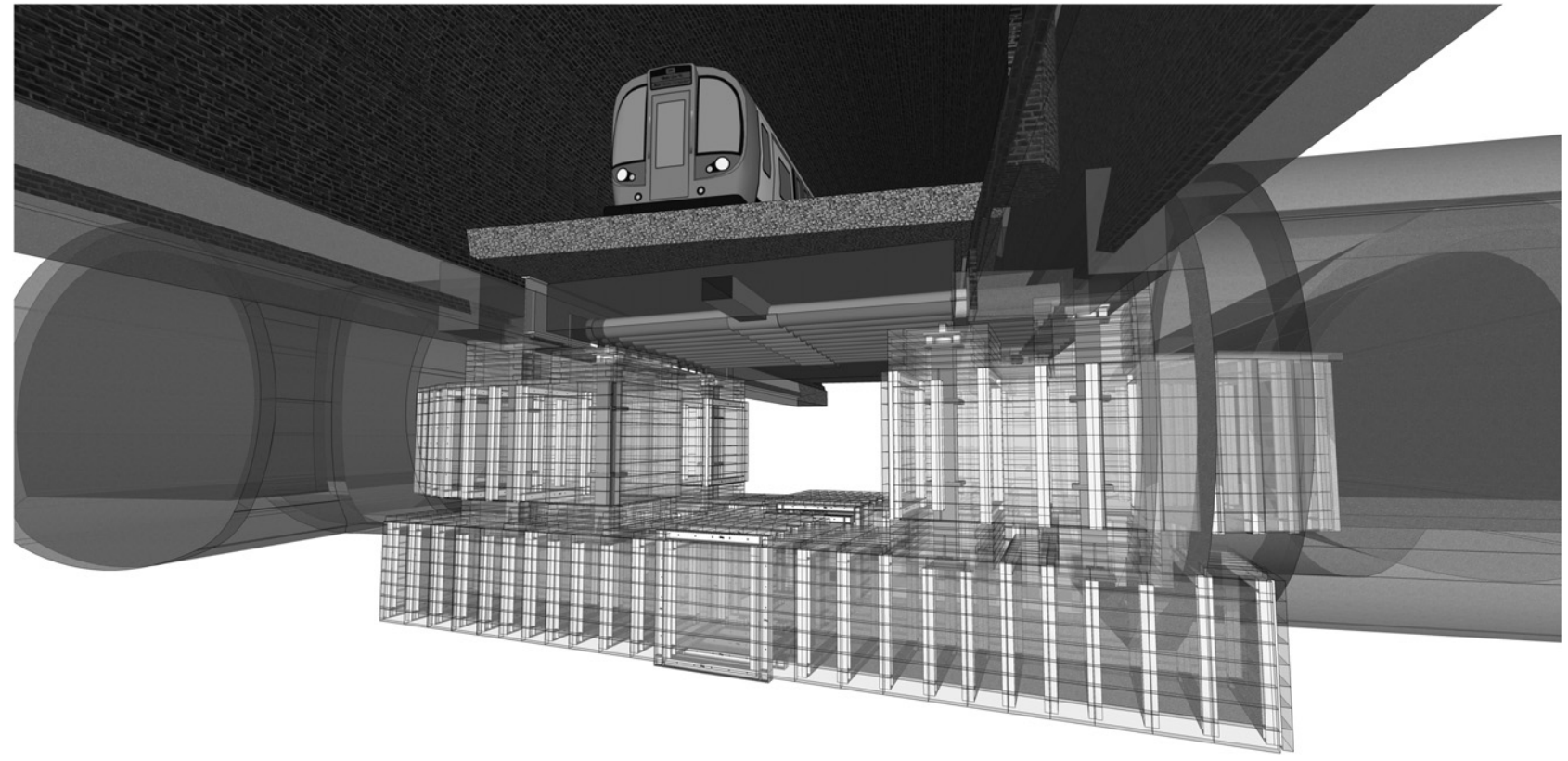

Figure 7. Pal6 temporary works heading configuration 


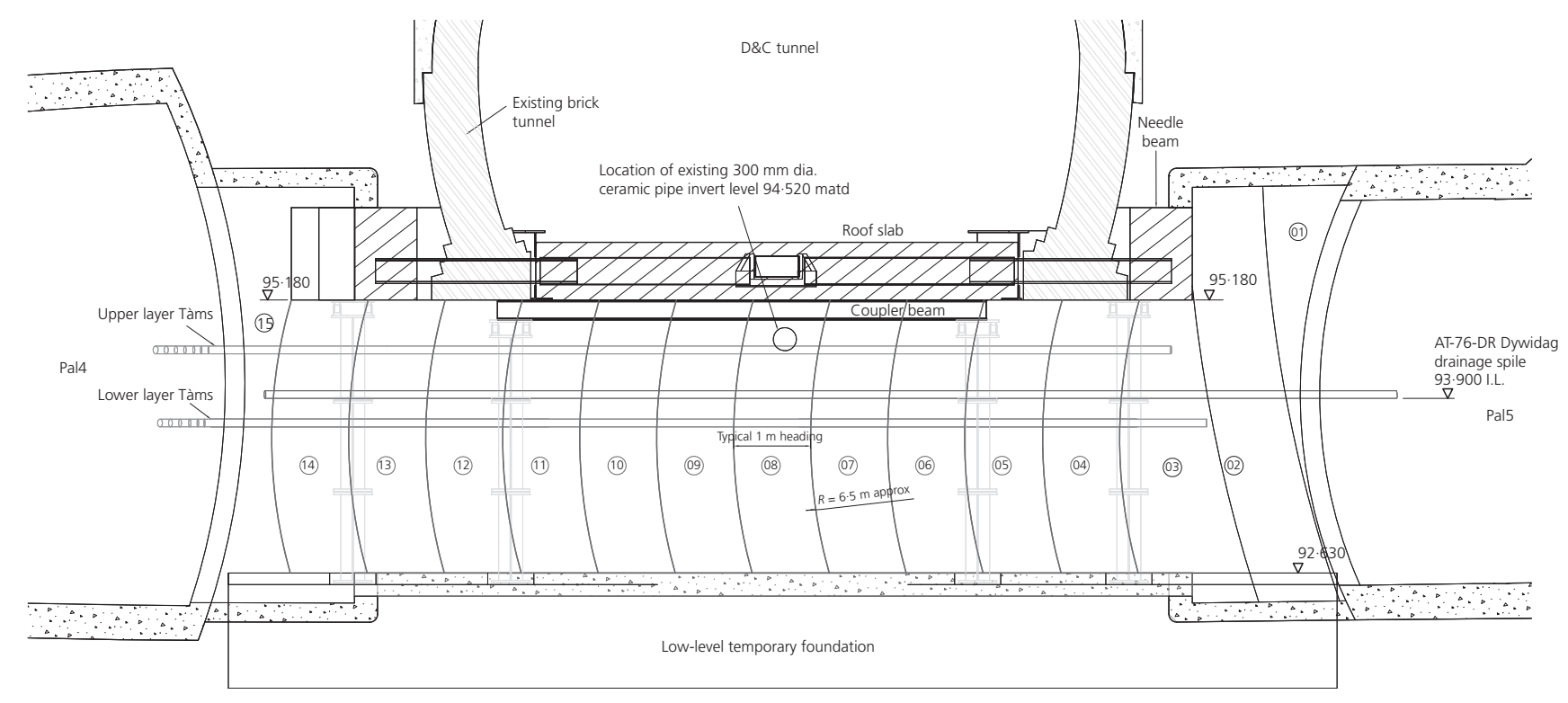

Figure 8. Heading sequence for bulk excavation

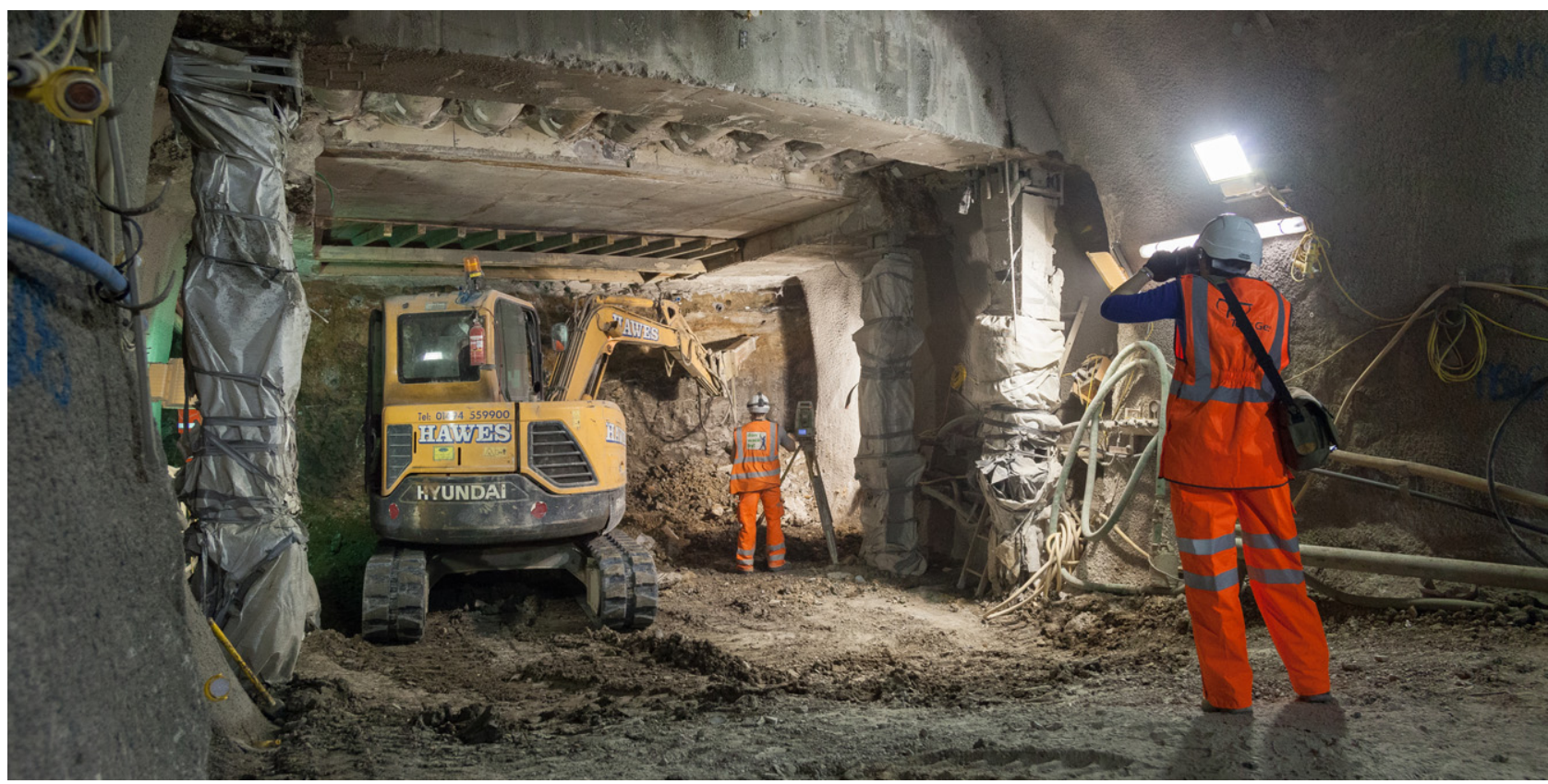

Figure 9. Bulk excavation

\section{Permeation grouting design}

Construction of the adjacent passenger relief underpass in the early 1990s proved extremely difficult, with limited success in permeation grouting and the occurrence of face losses. For Pal6, the difficulties were enormously magnified by the overhead D\&C line; ground loss could have proved disastrous, with even very small movements affecting operations (permissible track movements were limited to $4 \mathrm{~mm}$ ). Permeation grouting remained the most feasible option for stabilising the RTD, but only with significant improvements: the scheme needed to replace the RTD interstitial water (or gas) with grout injected at pressures low enough to prevent ground displacement.

The purpose of the permeation grouting was to provide sufficient stability to allow for safe excavation (through a reduction in soil mass permeability, thereby preventing 'running' 


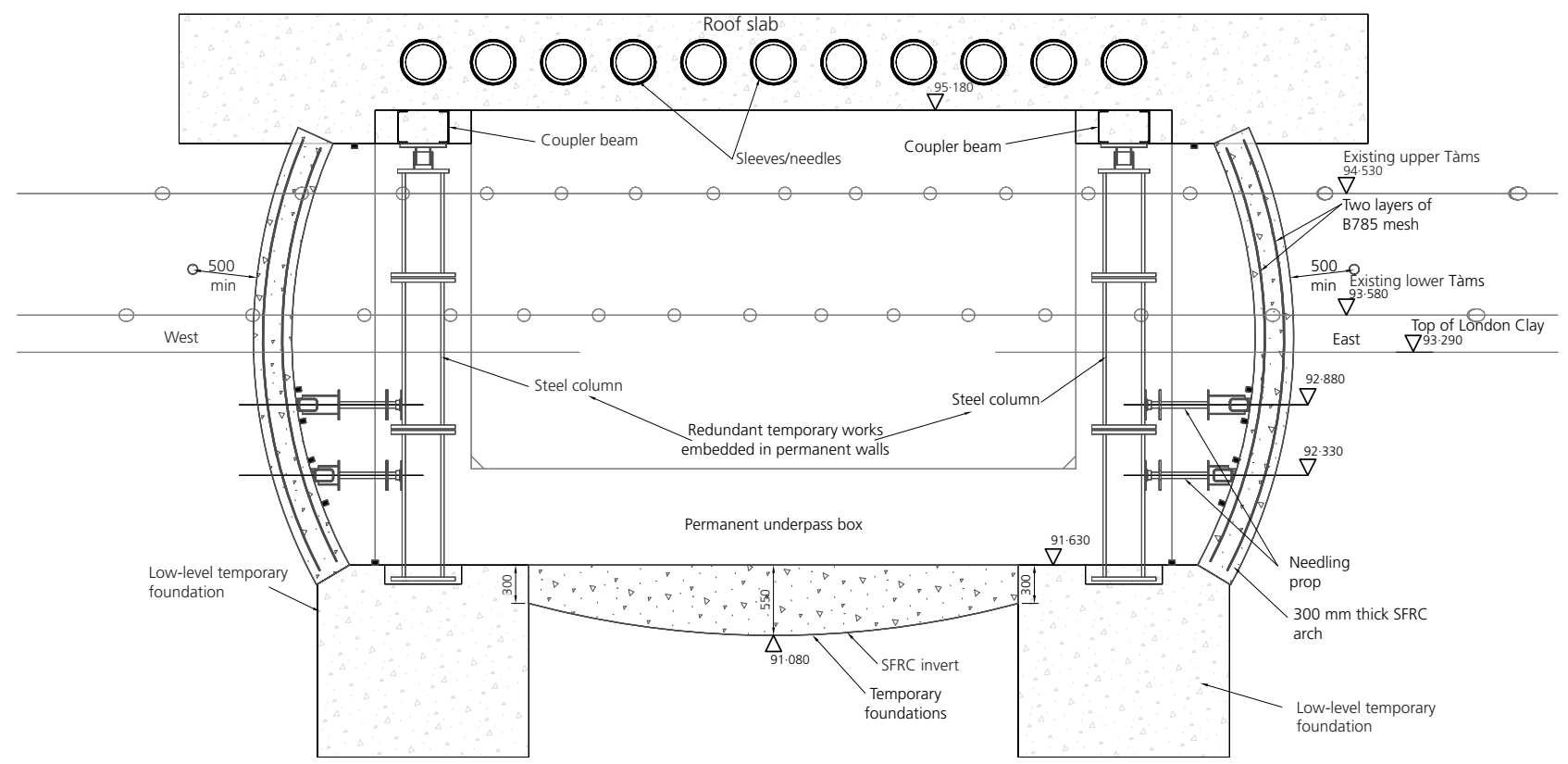

Figure 10. Pal6 integrated temporary works and permanent works

conditions) and to achieve adequate strength of the RTD soil volume lying between the underside of the D\&C tunnel and the surface of the London Clay. Design performance requirements were to reduce the residual RTD mass permeability by two orders of magnitude (to less than $3 \times 10^{-7} \mathrm{~m} / \mathrm{s}$ ) and produce a grouted RTD that exhibited an unconfined compressive strength of at least $1 \mathrm{MPa}$.

The grouted zone needed to extend a minimum of $2 \mathrm{~m}$ beyond the extrados of the Pal6 sidewalls, giving a total volume of soil requiring treatment of approximately $180 \mathrm{~m}^{3}$. Based on effective porosity estimates (from 0.33 to 0.39 ), this equated to a design grout volume of approximately $56500 \mathrm{~m}^{3}$.

Key construction stages in which reliance was placed on the strength and stability of the RTD included the following.

- Trimming of the D\&C tunnel concrete strip foundations to install the Pal6 roof slab. This increased the existing tunnel foundation bearing pressures by almost $40 \%$, from $400 \mathrm{kN} / \mathrm{m}^{2}$ to $550 \mathrm{kN} / \mathrm{m}^{2}$.

- Bulk excavation. The grouted RTD provided distributed support until the inner set of temporary support columns were installed. This temporary case imposed a bearing pressure of $320 \mathrm{kN} / \mathrm{m}^{2}$.

\subsection{Permeation grouting}

Continuous and extensive zones of silty RTD (with a fines content exceeding $15-20 \%$ ) that can prove particularly difficult to permeate were not observed in the 2013 investigation and, subsequently, it was apparent that microfine or ultrafine cements, in combination with a low-viscosity chemical grout, could provide the required ground improvement. The actual grout selection and design of the grout injection (including injection arrays, phases, grouting pressures and volume limits) were developed by the specialist grouting contractor (Strabag) to achieve the stipulated performance specifications (i.e. reduction of mass permeability and increased unconfined crushing strength post-treatment).

A reliable estimate of in situ permeability is fundamental to the success of permeation grouting and has a major influence on the assessment of groutability, the selection of grout types and injection methodology and its control. Littlejohn (1983, $1985 \mathrm{a}, 1985 \mathrm{~b}, 1985 \mathrm{c}$ ) indicated that the coefficient of permeability is the most useful single index of soil groutability. For particulate grouts, Littlejohn considered that permeability may set practical lower limits for grout injection by permeation and advised limits of

- $5 \times 10^{-4} \mathrm{~m} / \mathrm{s}$ for cement grout (mean particle size $\sim 90 \mu \mathrm{m}$ )

- $1 \times 10^{-5} \mathrm{~m} / \mathrm{s}$ for microfine clay cement grout (mean particle size $20 \mu \mathrm{m})$

- $1 \times 10^{-6} \mathrm{~m} / \mathrm{s}$ for chemical grout.

The particular grouting limits for the cement-based products (based on Littlejohn, 1983) are plotted in Figure 5 along with RTD permeabilities (determined from in situ tests and particle size distributions using Hazen's formula (Hazen, 1892)). These confirmed that cement grouting, other than with microfine cement, would not be successful in permeating the RTD except the coarsest fractions. To ensure that the 
permeation grouting would produce reasonably consistent treatment, greater emphasis was given to the lower bound rather than average permeability values. The focus on using the lower bound permeability estimates was also in reflection of the previously expressed limitations in the application of Hazen's formula to determine groutability.

As already mentioned, Hazen's formula potentially overestimates permeability correlations and therefore more reliance was placed on the in situ field tests. These test results were variable, ranging from $2 \times 10^{-6} \mathrm{~m} / \mathrm{s}$ to $6 \times 10^{-5} \mathrm{~m} / \mathrm{s}$. Within the elevations critical to the Pal6 tunnel, permeabilities varied from $2 \times 10^{-6} \mathrm{~m} / \mathrm{s}$ to $8 \times 10^{-6} \mathrm{~m} / \mathrm{s}$. The permeability tests carried out as part of the Pal6 site investigation were conducted within $50 \mathrm{~mm}$ dia. slotted standpipe piezometers. These falling head tests were completed in accordance with BS ISO 14686:2003 (BSI, 2003), using an automatic data logger.

\subsubsection{Tàms}

A major design consideration was the extremely low overburden (confining) pressures within the soils to be grouted (i.e. directly below the D\&C tunnel track level). Complete and consistent permeation of the RTD had to be achieved while ensuring ground displacements - particularly heave - did not disrupt the safe operation of the overhead railway. The importance of well-controlled injections demanded the use of a fanned array of horizontal steel Tàms, installed from the adjacent Pal4a tunnel. The general arrangement of the Tàms and sleeve positions is shown in Figure 11. The spacing and arrangement of the Tàms was dictated by the site's spatial constraints and the fact that they could only be installed from one side. The maximum spacing of Tàms at the far (most splayed) end was therefore not optimal. For this reason, once permeation grouting was completed, but prior to excavation, probing (and lance grouting if needed) was carried out from Pal5 to ensure these 'gaps' were sufficiently treated.

Horizontal drilling within the sands and gravels was achieved successfully through Strabag's specially designed proprietary blow-out preventer (Bop) system to avoid uncontrolled spooling of soil under water pressure at all stages of the operation. A starter hole was initially drilled to a depth of $300 \mathrm{~mm}$ and a steel casing with flanged connection was then grouted in place with a proprietary epoxy grout. The Bop system was

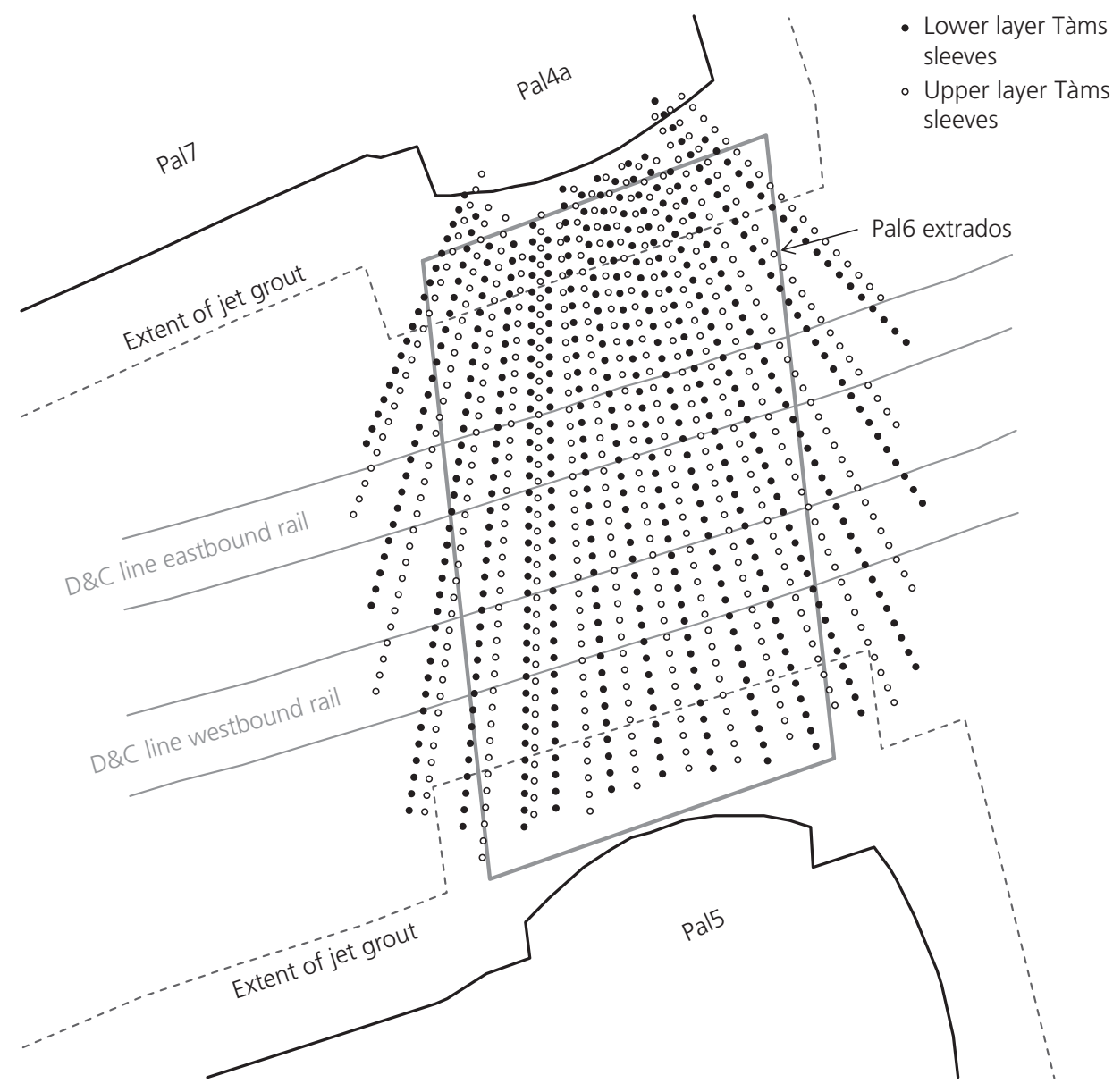

Figure 11. Tàms general arrangement 
then fixed to the flange and drilling was conducted through the Bop, adjusted to close around the drill casing. An integral, remotely detachable, drill bit was fitted with a one-way valve to prevent soil or water entering the casing. Once the required bore length was achieved, the Tàm pipes were then installed within the casing and the drill bit disconnected. The bore casing was withdrawn over the steel while simultaneously injecting low-strength grout (Heidelberg Zement Blitzdämmer 750 , allowing for a short setting time and low final strength) into the annulus. The Bop was then closed over the end of the Tàm pipe and the grout allowed to set.

The following parameters were recorded and continuously reviewed throughout the drilling phase: bore length, rate of penetration, thrust, rotation, torque, fluid flush pressure and flow, in addition to monitoring to ensure no ground or groundwater loss, and other general anecdotal observations during drilling (such as other VSU construction works occurring in parallel).

Rupture pressure is the pressure measured, displayed and recorded at the beginning of the grouting process at each sleeve, and is 1.5 to 2.0 times the grouting pressure at the actual pumps. The rupture pressure reflects the pressure required to push the rubber sleeve off the steel Tàm and to crack the perimeter grout to form a flow path into the surrounding soil. As more and more grouting circles are applied, this pressure increases because not only the perimeter grout needs to be cracked but so does the previously injected grout body in order to achieve a flow path. Grouting trials (using water and then cementitious grout) were carried out to establish and confirm grouting parameters.

\subsubsection{Selection of grouts}

The injection phases involved microfine and then ultrafine cement grouts (BASF MasterRoc MP650 and Mikrodur X, respectively) to permeate the slightly coarser soil fraction and impart strength. The more costly chemical grout (BASF MasterRoc MP320) was then used to permeate the finest soil fractions, achieving the overall permeability requirements. The chosen chemical grout was a nanometric colloidal silica suspension with a viscosity of $\sim 5 \mathrm{mPa}$.s (only four to five times that of water); it was an inert grout with exceptional penetration properties, zero syneresis and no shrinkage.

Grouting works were carried out during nightly engineering track closures. This allowed for continuous real-time monitoring of the D\&C tunnel structure and track levels, with instant relay of results to the Pal6 grouting team below.

\subsubsection{Sequencing of injections}

Sequencing the injection phases was important to minimise the risk of residual ungrouted pockets and to prioritise areas directly below the D\&C foundations, enabling the in-tunnel works (installation of the Pal6 roof slab) to progress unimpeded. The injection consisted of the following four main stages.

(a) Microfine grout at the eastern upstream boundary was first injected to provide an initial cut-off to external groundwater flow. This was then followed by microfine grouting along the western (downstream) boundary to act as a confining perimeter barrier for the subsequent grouting stages.

(b) Microfine grouting to target the coarser grained soils within the remaining central area (focusing on upper row of Tàms directly below the existing $\mathrm{D} \& \mathrm{C}$ foundations, followed by the lower Tàms row).

(c) Ultrafine grouting to target medium- to coarse-grained soils across the entire design volume (including upstream and downstream boundaries).

(d) Chemical grouting to infiltrate the smallest pore spaces across the entire design volume.

At no time was grout injection carried out in adjacent Tàms sleeves; instead, alternate sleeves were used to minimise the risk of heave at any one time. This also enabled a slow buildup of treatment and the ability to gauge its effectiveness at each stage. Each grouting phase commenced with injection using the most distal sleeve location, then gradually progressing closer to the Tàm collar. All mixers, pumps, packers, hoses and agitators were properly cleaned with water after grouting and in between grouting stages. Additionally, each Tàm was cleaned with water and brushes after grouting to avoid blockages.

\section{Success of permeation grouting}

Carefully controlled procedures in combination with real-time D\&C tunnel and track monitoring allowed the grouting works to be successfully completed.

\subsection{Installation of Tàms}

During drilling and installation of the Tàms, D\&C track levels immediately above the Pal6 underpass footprint were surveyed at 36 discrete locations by the principal contractor (Taylor Woodrow-BAM Nuttall joint venture) at regular frequencies to identify any changes in track levels. Observed ground heave in terms of recorded track displacements during drilling and installation of the Tàms indicated peak vertical movements of 3-4 mm, with an average of $3.3 \mathrm{~mm}$ heave for installation of an individual Tàm. The configuration of the Tàms installation from the Pal4a headwall is shown in Figure 12.

\subsection{Grout injection}

During grouting works, the D\&C track levels were regularly surveyed and differential track movements were correlated with total injected grouting volumes for each shift. These were reviewed daily at technical briefings. The original design injection sequence was accordingly adjusted during the grouting works in response to observed movements at track level within 


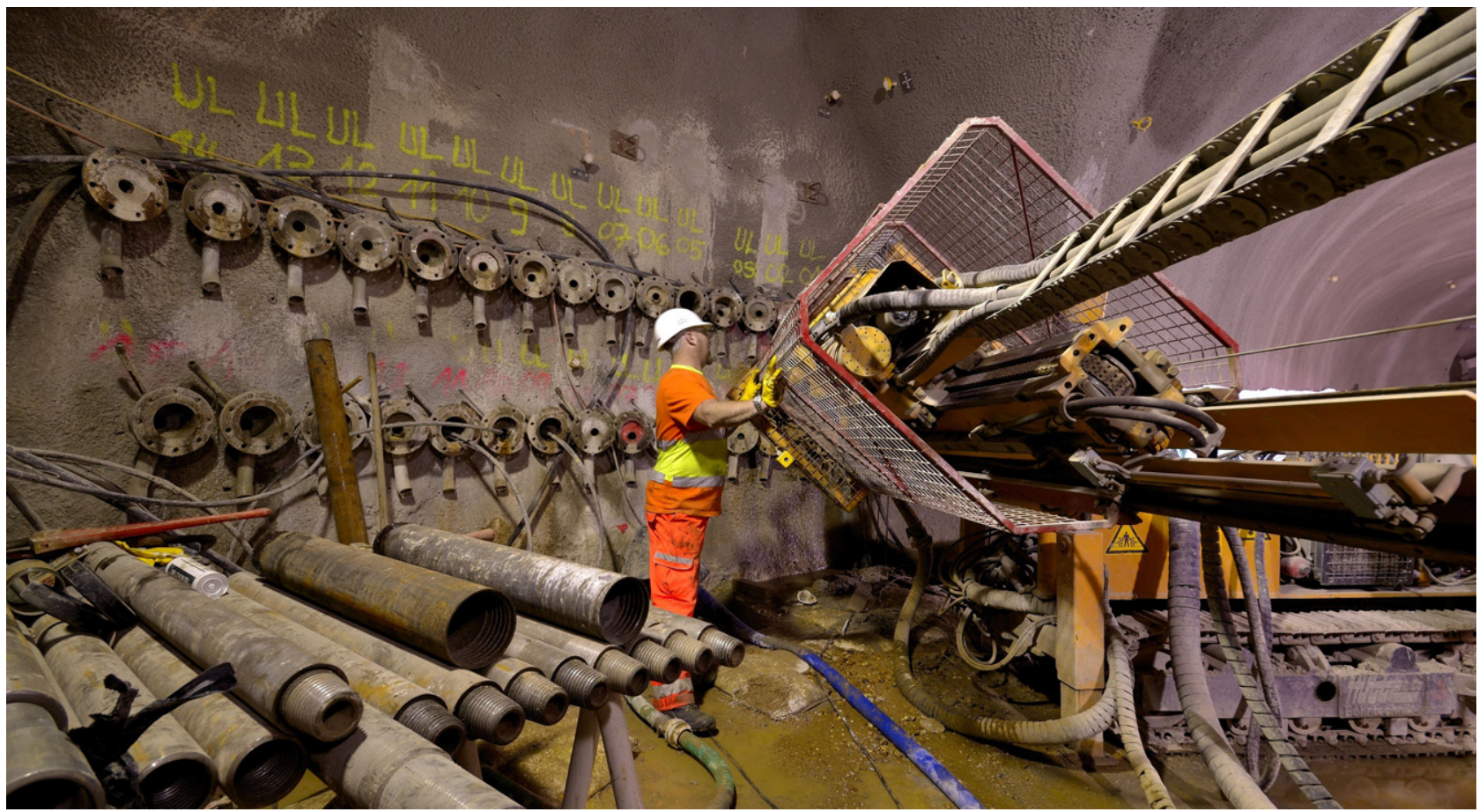

Figure 12. Installation of Tàms

the D\&C tunnel. Track movements (and higher than anticipated grouting pressures) recorded during the initial injection phases of the cement grouts resulted in the sole use of the lowviscosity colloidal silicate chemical grout for all subsequent grouting phases. The track movements implied some fracturing during injection of the cementitious grouts. Typically, the observed track movements corresponded with the Tàm sleeve locations in use. Movements not coinciding with the locations of grout injection indicated that the grout had migrated away from the intended target zone (surrounding the injection sleeve), which may have thus resulted in potentially incomplete treatment at that location. It should be noted that the D\&C tunnel masonry structure itself had almost negligible recorded movements throughout the Tàm installation and grouting phases.

Simply to prevent heave and encourage permeation, the grouting pressures and volumes for individual Tàm sleeves were limited to predefined values by the specialist grouting contractor. The contractor provided an injection control unit that allowed for full control of pressures, injected volumes and flow rates. Generally, a two-stage pressure limitation was utilised, involving a higher value initially to allow for forcing the grout through the sleeves at the start of each injection and then a lower set pressure based on a calculated design value. Flow rates were adjusted automatically to maintain the maximum pressure or, alternatively, the injection was halted. The pumps were dual-acting piston pumps controlled by the injection module software. Maximum working pressures during grouting were limited to 5 bar $(0.5 \mathrm{MPa})$ for the upper Tàm row and 8 bar $(0.8 \mathrm{MPa})$ for the lower row (based on experience in similar ground conditions and field grouting trials). Grouting pressures were controlled in practice by ensuring ground heave was minimised while maintaining a balance between the rate of injection and pressure: if the pressure is too low then injections become very protracted. The critical injection volume was based on the perceived radius of influence for each sleeve and a predetermined track cumulative heave limit of $4 \mathrm{~mm}$. The critical injection volumes per sleeve were 281 and 751 for the upper and lower Tàm rows, respectively. Recorded movements of the D\&C track monitoring points were used to backcalculate the individual sleeve influence zones and allowable sleeve injection volumes were then reconsidered for the subsequent grouting phases.

In total, 107321 of cementitious grouts (8014 1 of MP650 and 27181 of Mikrodur X) and 362811 of the low-viscosity colloidal silica grout (MP320) were successfully injected. These amounts corresponded to approximately $108 \%$ of the initial design volume. Observed track movements above the Tàm sleeve locations during the cementitious grout injections were typically $0.8-1.0 \mathrm{~mm}$. The cumulative effects on the highly sensitive overhead railway tracks meant that tamping of the tracks was necessary on one occasion. However, due to severely restricted working hours during engineering hours and the overall VSU programme deadlines, at approximately halfway 
through the grouting works the decision was made to use only the colloidal silica grout (MP320) for the remaining injections. Although the grout costs were higher, these were outweighed by the economic implications of potential further tamping or the costs associated with obtaining track closures.

\subsection{Verification testing}

Once permeation grouting was complete, an extensive verification testing sequence was carried out to validate the minimum design requirements of permeability, strength and consistency. Testing methods included staged drilling to assess horizontal borehole stability, water inflow and in situ permeability. The in situ strength was measured through pressuremeter testing and laboratory compressive strength testing on soil/grout cube samples. On completion of these tests, the results were reviewed to identify any residual areas of potentially poorly grouted soils; these were subsequently targeted for further systematic probing and lance grouting during excavation stages. The lances were able to grout up to $3 \mathrm{~m}$ ahead of the headwall, and were sealed using a packer system. Silica grout was used for the hand-mining works during prop installation and cementitious grouts were used for the bulk excavation headings (as the newly installed Pal6 roof slab at this stage restricted any induced ground heave).

Pressuremeter testing within the grouted RTD indicated satisfactory unconfined compressive strengths. The results were interpreted upon the assumption that the surrounding ground was fully grouted and therefore acting as a pseudo-cohesive material in an undrained manner. Interpretation was also reliant on the careful insertion of the pressuremeter probe and full connection of the expanded vessel with the surrounding soil. Where successfully tested, the interpreted pressuremeter results (using the method proposed by Gibson and Anderson (1961)) for the permeation-grouted RTD ranged from 1.2 MPa to $6.8 \mathrm{MPa}$, similar to that of weak rock.

In situ permeability (falling head) tests and observations of water inflow during the drilling of verification boreholes were used to estimate the permeability of the grouted block. It was apparent that there were isolated instances of wet ground. Larger, more continuous, sections (4-5 m long) of apparently partially treated ground were also observed, with some tests in the southeast corner indicating permeabilities greater than the target $3 \times 10^{-7} \mathrm{~m} / \mathrm{s}$. These areas of concern were subsequently targeted for further probing and lance grouting.

\subsection{Mitigation measures and bulk excavation}

From the verification testing it was apparent that much of the area within the design permeation-grouted soil block had achieved the required strength and permeability. Uniform treatment was critical because it reduces the risk of isolated, or potentially connected, pockets of trapped water and unstable ground. To further mitigate the potential risks of untreated soil (both in areas identified from verification testing as potentially incompletely grouted and elsewhere) and allow for safe excavation, systematic probing and lance grouting were carried out as part of the prescribed construction methodology. Additionally, prior to excavation, horizontal drains (Figure 8) were installed upstream of the grouted soil block to assist in reducing lateral water pressures on the temporary Pal6 SFRC sidewalls.

The excavation/ SFRC construction methodology followed a specific sequence of works, including real-time highly focused monitoring, both within the Pal6 underpass and in the overlying D\&C tunnel. Trigger limits were specified (and agreed) prior to any excavation. Daily review meetings were held throughout the entire Pal6 construction.

Excavation was carried out using mini-excavators during continuous $24 \mathrm{~h}$ working shifts over a period of approximately $12 \mathrm{~d}$. Excavation was completed in a series of $131 \mathrm{~m}$ advances, with $300 \mathrm{~mm}$ thick SFRC being installed as temporary sidewall support, arching between the roof slab and temporary foundations. The sequencing of the works was such that the cut soil face for each advance was fully exposed for the smallest duration possible (typically $4 \mathrm{~h}$ ).

The grouted RTD encountered during the excavation acted effectively as an impermeable barrier to groundwater inflows from beyond the design grout envelope and provided very stable self-supporting near-vertical faces. Figure 13 illustrates a fully exposed freshly cut advance headwall, which was fully self-supporting for the temporary case (up to $6 \mathrm{~h}$ ).

\section{Protection of third-party assets}

As part of the geotechnical design, detailed three-dimensional (3D) finite-element (FE) models were used to predict ground movements associated with the individual construction stages. This was to ensure no unacceptable structural effects were imposed upon adjacent third-party assets. In addition to the D\&C tunnel, sensitive subsurface structures included three cast-iron sewers running parallel and perpendicular to the Pal6 centreline. Adjacent Pal tunnel structures (Pal4a, Pal5 and Pal7) were included in the FE modelling to address the construction of these structures and their influence on the overall ground displacements.

Two constitutive soil models were incorporated in the FE analyses: (a) the Mohr-Coulomb failure criterion and (b) the hardening small-strain soil model (used only for the London Clay due to the availability of relevant laboratory test data).

The initial 3D FE modelling indicated that the majority of the ground movements were due to the construction of adjacent Pal tunnels rather than Pal6 itself, with maximum long-term ground surface settlements less than $10 \mathrm{~mm}$. Potential damage assessments (prior to construction) of the D\&C tunnel and 


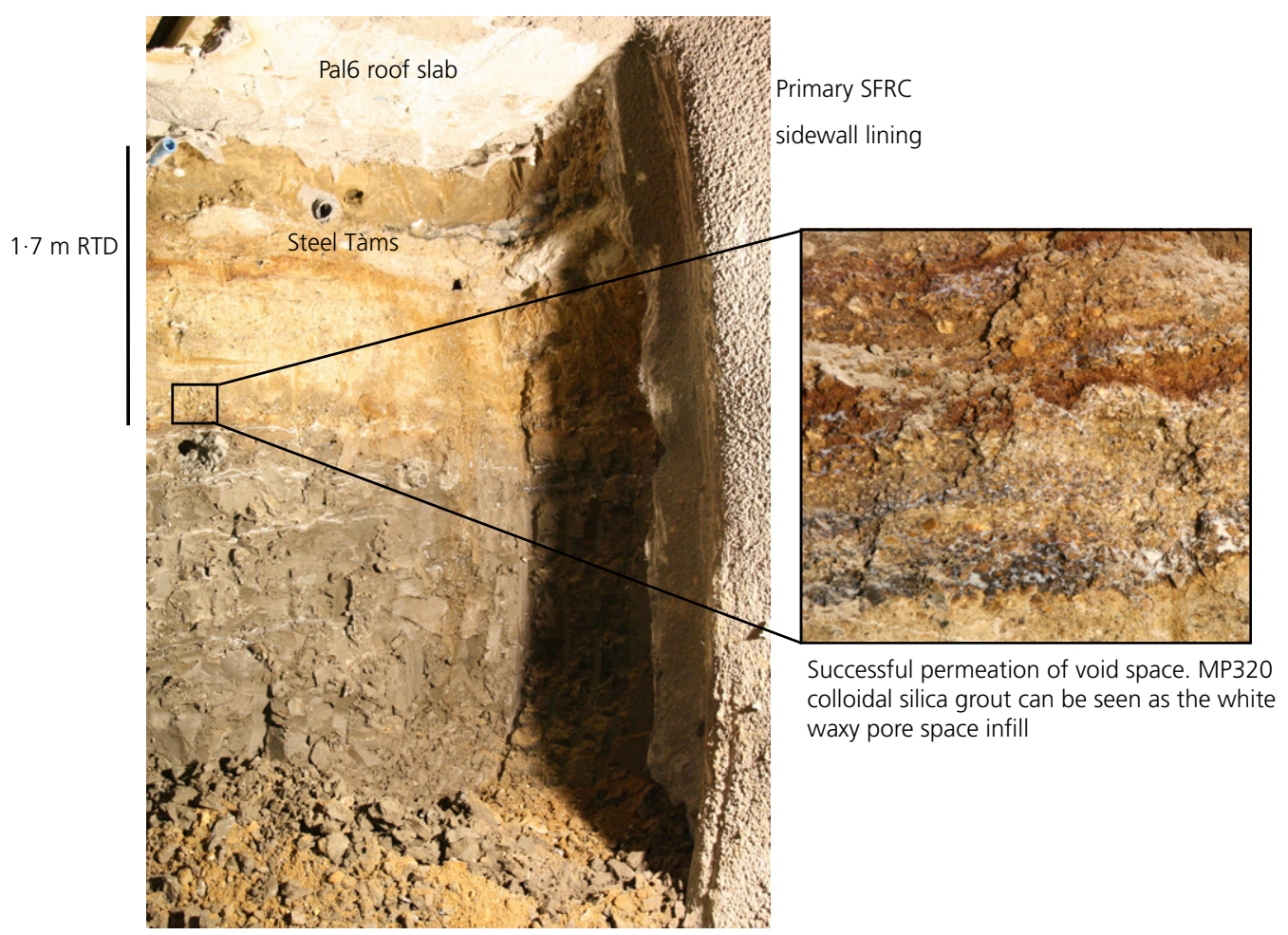

Figure 13. Photographic evidence of successful permeation grouting during bulk excavation

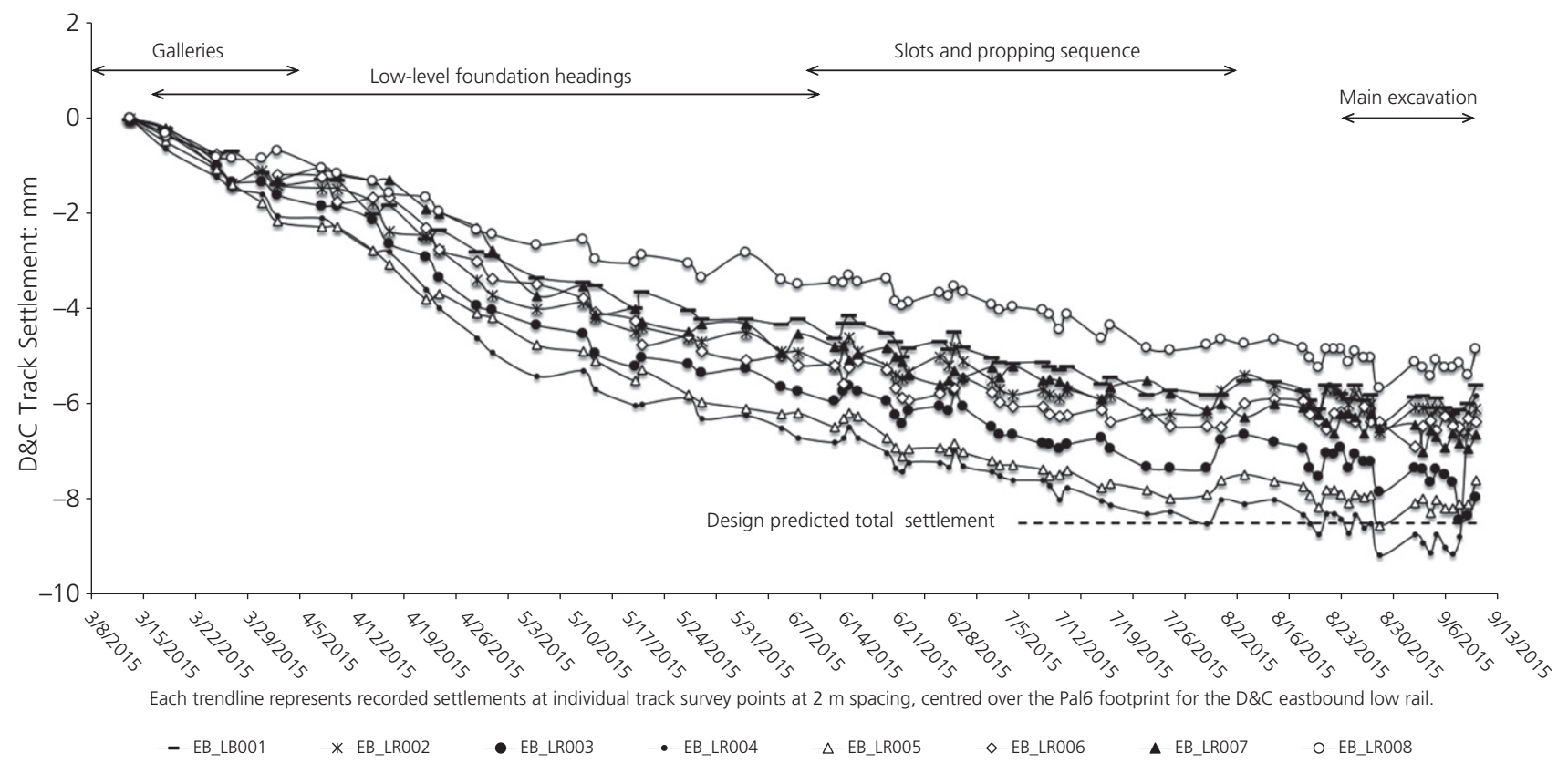

Figure 14. Recorded track movements during Pal6 construction

sewer assets indicated ground displacements were within allowable structural strains and distortions, thereby supporting the validity of the permeation grouting.
Throughout the investigation and construction process, the FE design models were revisited, updating soil properties with actual tested soil strengths as well as back-calculating 
permeation grouted soil strengths from recorded movements. After key construction stages, the final, overall, ground displacement calculations were reviewed to enable more accurate predictions. These refined displacement predictions allowed for optimisation of construction phasing: for example, consolidation of individual construction stages being performed concurrently (rather than independently) during a single track possession and approval of some works to be carried out during operation of the overhead railway.

Figure 14 illustrates the recorded track movements during Pa16 construction and the initially predicted overall settlements from the FE analyses.

\section{Conclusion}

Successful permeation grouting, along with real-time monitoring systems, and a carefully sequenced (and continuously reviewed) excavation enabled safe operation of the D\&C line at all times and protection of its structural integrity, in addition to other third-party subterranean assets. Actual ground displacements measured during the Pal6 construction were less than those predicted during the design process.

The rather crude ill-controlled grouting in the 1990s used lancing grouting, which was far inferior to the targeted and repetitive injections offered by the Tàm system. Grout leakage was significantly less using the Tàms and the Tàm system promoted permeation of the ground rather than flow along the weakness created by driving in a lance. Additionally, the site investigation and rota-sonic coring allowed for matching of grout types to accurate particle size data and its variations. Accurate characterisation of the soil zones to be targeted during grouting with a highly specified site investigation was key to validating the suitability of permeation grouting, without which the proposed Pal6 construction scheme was unviable. Detailed delineation of the ground, and thereby appropriate selection of grouts, was a critical component in engaging the support of the principal contractor, client and other stakeholders, allowing for significant reductions in D\&C track possessions and reducing impacts on the overall VSU programme.

The grouted RTD very effectively facilitated bulk excavation of the mixed-face Pal6 conditions using a carefully controlled heading and SFRC sequence. The integrated design role throughout the construction process allowed for further economies to be made during subsequent key stages.

\section{Acknowledgements}

The authors would like to acknowledge London Underground Limited (overall client for the VSU project), Taylor WoodrowBAM Nuttall (principal contractor and client), Strabag (specialist grouting contractor), RD Geotech Ltd (specialist grouting advisor) and Concept Engineering Consultants Ltd (site investigation contractor).

\section{REFERENCES}

BSI (2003) BS ISO 14686:2003: Hydrometric determinations. Pumping tests for water wells. Considerations and guidelines for design, performance and use. BSI, London, UK.

Gibson RE and Anderson WF (1961) In situ measurement of soil properties with the pressuremeter. Civil Engineering and Public Works Review 56(658): 615-618.

Hazen A (1892) Some Physical Properties of Sands and Gravels, with Special Reference to Their Use in Filtration. Massachusetts State Board of Health, Boston, MA, USA, 24th Annual Report, Document 34.

Lambe TW and Whitman RV (1969) Soil Mechanics. Wiley, New York, NY, USA.

Littlejohn GS (1983) Chemical Grouting. South African Institution of Civil Engineers (Geotechnical Division), University of Witwatersrand, Johannesburg, South Africa.

Littlejohn GS (1985a) Chemical grouting - 1. Ground Engineering 18(2): 13-16.

Littlejohn GS (1985b) Chemical grouting - 2. Ground Engineering 18(3): 23-28.

Littlejohn GS (1985c) Chemical grouting - 3. Ground Engineering 18(4): 29-34. 